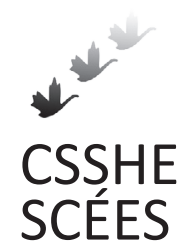

Canadian Journal of Higher Education Revue canadienne d'enseignement supérieur

Volume 45, No. 1, 2015, pages 136 - 147

\title{
The First Cycle of Study: Teaching and Learning at Cross Purposes?
}

\author{
Réal Fillion \\ University of Sudbury
}

\begin{abstract}
The contemporary university has grown to be a fairly complex institution sustained by many competing interests, not all of which are directly concerned with promoting the work of study, broadly conceived. My concern in the following is with the quality of the subjective experience of studying that universities are still meant to provide. By subjective experience I mean the mindful engagement that is study, and my focus is on such study as it is found in undergraduate programs leading to undergraduate degrees. Given the threat of a growing indifference between professors and students concerning their shared engagement in courses offered at the undergraduate level (offered because of professors' institutional obligations, taken because of students' degree requirements), I reconsider the subjective investment of mindful engagement that these courses nevertheless represent.
\end{abstract}

\section{Résumé}

L'université d'aujourd'hui est devenue une institution très complexe, où rivalisent plusieurs intérêts dont l'objectif premier n'est pas toujours d'encourager le travail de l'étudiant entendu au sens large. Le texte qui suit s'inquiète de la qualité de l'expérience subjective des études que les universités sont encore supposées procurer. Par " expérience subjective » j'entends l'engagement de l'esprit, qui est ce en quoi consistent les études, et je m'intéresse particulièrement ici aux études telles qu'entreprises dans des programmes de premier cycle menant à la diplomation. Étudiants et professeurs affichent de plus en plus une indifférence envers l'engagement qu'ils doivent avoir les uns envers les autres dans les cours de premier cycle (offerts par les professeurs en raison d'obligations institutionnelles, et entrepris par les étudiants en raison des exigences du programme). Devant cette menace, je réexamine l'investissement subjectif que ces cours requièrent néanmoins en tant que lieux d'un engagement de l'esprit. 
The contemporary university has grown to be a fairly complex institution sustained by many competing interests, not all of which are directly concerned with promoting the work of study engaged in by the "community of masters and scholars" that originally coalesced to form the university as a distinctive feature of the world nearly a thousand years ago. However, my concern in the following is not with the objective structures and "outputs" of the contemporary university, but rather with the quality of the subjective experience of studying that universities are still meant to provide. By subjective experience, I refer to the mindful engagement that is study, and my focus will be on such study as it is found in undergraduate programs leading to undergraduate degrees (in the arts, more specifically, given my expertise).

I characterize study as "mindful engagement" for two interrelated reasons. The first is to emphasize that studying actively engages the mind. This is obvious, of course, but it is worth emphasizing because in our thoroughly "schooled" society, "studying" can quickly be understood as a kind of social occupation rather than a specific form of intellectual engagement, contrasted with "working" (gainful employment) or, indeed, "playing" (leisure activities), for example. In this sense, students can see studying as something they do but not necessarily something that engages them at some more fundamental level (largely, they are doing what they are told to do, and often are quite happy to do so). The second reason is that this intellectual engagement can be more or less attentive to its character as a specific engagement of the mind and for the mind. That is, when we are engaged in study, we are not only using our minds, we are actively engaged in shaping them in certain ways. To be mindfully engaged in study, then, is to be attentive and attuned to this self-shaping activity. It is the quality of this attentiveness in both professors and students, in their subjective encounters, that is my primary concern.

My focus is on undergraduate study, not only because I am principally engaged in undergraduate teaching, but also because, arguably, the undergraduate university degree, broadly considered on its own terms, is in its conception meant to address the mind as this self-shaping potential. This is one way of expressing its distinctiveness as a form of study-different from either vocational training or professional formation but also different from the kind of study typical of high schools, with their ministry-approved curricula and focus on preparing the student for either the workforce or further forms of study. This self-shaping potential of the mind probably reveals itself best in those courses that students take freely, that is, not as a program requirement but out of something like an unfettered interest and curiosity - a free engagement of and with one's own mind.

In order to think through the subjective experience of engaging university study from this perspective, I find it useful to employ the French term for these "undergraduate" years: the first cycle of study (le premier cycle d'études). This particular expression is a good reminder, as Alfred North Whitehead (1929/1967) noted years ago, of the rhythmic character of learning (which he himself characterized as cycling itself through stages of the romance of discovery, issuing into the work of precision, itself giving way to the possibility of generalization, the last especially relevant at university), and it gives this freely undertaken mindful engagement that is university study its own particular context: a round or cycle of courses that maps out an initial (largely) disciplinary engagement with various subject matters (some of them introduced to the student for the first time), without immediately subordinating that engagement with studying to the concerns of gradu- 
ate study and the increasing specialization thereby promoted. Such a round or cycle of courses currently completes itself in the awarding of a degree (a bachelor's degree). It can then issue into renewed cycles of courses (at the master's level and then the doctoral level), but it need not. In fact, many students do not even complete the first cycle-this does not mean, however, that they have not had the opportunity to engage in mindful study.

From the subjective perspective, then, when one engages in university studies, one freely engages in various courses of study. These can be more or less mapped out, into programs, degrees, certificates, and whatnot. And you can follow them as they are mapped out, doing what those in charge of developing and delivering them ask of you. However, I suggest that this is not yet to engage fully in university study. It is too close to doing what one is being told to do, on the model of compulsory education. What is important about university courses of study, from the perspective of the mindful engagement they appeal to, is that they are self-consciously developed as courses-that is, something that engages your attention along a proposed path, that follows the movement of thinking about something in a particular, determinate way, carefully distinguishing what is relevant from what is not. We say that we take such courses, but if we are studying by means of them, it is less a question of taking possession of something than it is a question of opening oneself to what they offer, like when we take this route rather than another in order to take in the view.

Again, from the subjective perspective, it is important to remember that these courses are offered by professors and taken by students. Whatever the program and degree requirements might be, university courses are proposed, prepared, and given by individual professors to individual students who freely select and attend them. It is the quality of this mutually mindful engagement of offering and taking that is worth underscoring. I am becoming increasingly concerned that the courses I offer within the first cycle of study, rather than being seen as the opportunity they are to exercise the kind of mindful attention that studying affords, resemble opportunities squandered (to become, instead, something gotten through on the way to a degree or-for the professor-to a pay cheque or time to do other things). Part of my response to this involves a reconsideration of what and how I teach, but that is not the subject here. Instead, I want to turn my own mind to mindful attention itself and offer an account of how it engages us in the context of university studies.

If our concern here is study as mindful engagement subjectively conceived, I should say something more about how I am using the term "subjective." I am following the German philosopher G.W.F. Hegel (1770-1831) in his careful and systematic consideration of our mindful engagement with each other (Hegel, 1830/2007). For Hegel, the reality of subjective mind (as distinct from what he calls "objective mind," exhibited in the systematic and institutionalized patterns of interaction we constitute for ourselves as we intend just relations, and "absolute mind," which deals with what we consider to be of ultimate significance) can be systematically appreciated through attention to its increasing selfdetermination, starting from the establishment of a kind of psychic coherence, giving rise to conscious awareness, and eventually developing an intelligent grasp of the world. These three dimensions of our subjective minds are not three separate things, but rather, as Richard Dien Winfield (2010, p. 5) puts it, "are successive stages in the self-constitution of the totality of mind." A consideration of our subjective mindful engagement in the context of university study, then, should explicitly address this self-constitution. From this perspective, I would say that university study is subjectively about the free and cre- 
ative engagement of our intelligent appreciation of each other and the world as it grows out of-and challenges through openly questioning-our (psychically) habituated sense of ourselves and the self-conscious desires this affords. It does this through the focus on the free choice of courses and programs (including the academic freedom of the professors to propose them). Such free and creative engagement cannot be a matter of indifference; indeed, the manifestation of indifference within our shared mindful engagement in study is a kind of betrayal of the very bonds that constitute its possibility. That such indifference does seem to be manifest within our contemporary universities is at least partly a result of the insufficient appreciation of the fact that our subjective mindful engagement in study is indeed something that is constitutively and creatively shared. When we fail to appreciate this, each of us tends to fall back on the unreflective reliance on the cogency of the habitual practices that structure our everyday lives, as these move us through our days. But if we notice this indifference-along with its insufficiency as a mode of free and creative mindful intelligence, as a fuller engagement with the totality of our minds-we can begin to address it.

How can I, as a professor preparing and offering courses, be indifferent to our shared mutual engagement in study that such courses enable?

How can you, as a student registering in and taking (in) such courses, be indifferent to that same shared mutual engagement?

An obvious answer is to say that, in reality, neither the professor nor the students typically see themselves in these terms. Alhough the course does indeed mutually engage them, they do not see that mutuality as a shared engagement, but rather as something to go through in order to be able to do something else, something more important, something that does engage their free and creative intelligence. Perhaps for the professor this is her research, and perhaps for the student it is various activities other than study, inasmuch as he sees the courses he takes as part of a degree he seeks to obtain in order then truly to engage his free and creative intelligence in a satisfying job and career. As Derek Bok (2006, p. 286), past President of Harvard University, puts it-and we will come back to his views presently-students

want work that is interesting, well paid, respected, and worthwhile. They want to serve in an ethical environment where they do not feel pressured to do things they consider wrong and can count on being judged fairly in matters of pay and promotion. They want a career that fits their aptitudes and talents yet challenges them in ways that help them develop further.

Note that Bok is describing what students ultimately want out of their "education," and he can be seen here as gently chiding them in imagining that this is in fact what their engagement in university studies will give them. (This comment follows a brief discussion of the "unrealistic expectations" of entering law students and architecture students who imagine for themselves lives that do not reflect the lives most graduates of these schools will go on to live.) After college, they will still need to find the work that they will have spent the last number of years "preparing" for. This reminds us that there is, for the most part, no direct link between the kind of study that universities provide (most obviously in the arts) and the kinds of activities asked of us in order to "make a living." This question is being addressed, of course, insofar as universities continue to take on more and more 
professional and vocational programs. But it remains relevant to distinguish programs of study or instruction geared towards preparation for the execution of specific tasks from the kind of study constituted out of the open questioning of what we already know. Indeed, we might paradoxically suggest that the subjective point of engaging the first cycle of study (for both professors and students), outside of the context of professional formation or vocational training, is to pursue something like "knowledge" in the spirit of not knowing, of opening one's mind to the questioning of received views and exploring what else is to be "known" besides what one has so far been given to know (through practices of schooling and work).

Of course, the description of universities I am giving here may sound somewhat strange, especially when we consider how they are meant to play a crucial role in what is called the "knowledge economy," and how they are marketed within that economy. And yet I will insist that universities are primarily places of "not knowing" and "study," and specifically places where these come together. Again, as mentioned above, universities are fairly complex places that gather many different practices and interests; my claim here is that the core of the university remains the engagement of study in the spirit of not knowing. In this I am merely following Socrates in his observation of the paradoxical character of knowledge. If we pursue knowledge, this implies that we do not possess it. But if we do not possess it, how will we recognize that we have found it? And if we do at some point finally claim to possess it, why do we promote its continued pursuit? Consideration of this paradox has, for me, the salutary effect of reminding me that whatever claim to knowledge I encounter (whether as formulated by me or by others), precisely because it is encountered, is an invitation to study. And insofar as it is such an invitation, it falls within a conception of knowledge as a pursuit and not a possession. Universities, then, in my view, are places where knowledge is pursued (and claims to knowledge are proposed and assessed), not places where knowledge is possessed; they are places of study.

Another way to put this is to say that universities are places specifically devoted to the life of the mind in its pursuit of knowledge, animated by the sense that what is given to us is insufficiently comprehended and requires the kind of attention that is called study. In the context of our discussion here, engaging the first cycle of study is critically engaging the limits of one's own mind and reshaping it, not by acquiring knowledge (that one can then be said to "possess") but by pursuing it. This pursuit engages both the professor and the student; they are thus both animated by a spirit of "not knowing," the professor serving as a guide to the work such a pursuit involves.

In these terms, then, perhaps the problem of indifference or lack of mutual engagement stems from the failure to appreciate to what extent the first cycle of study can, in effect, be a place for the open questioning of what we already know. For the student, such a failure would follow from the overriding expectation that his study should lead to a job; for the professor, it would follow from the expectation that real questioning is reserved for those adequately disciplined and prepared (i.e., graduate students).

While I do think that this failure of appreciation exists, and that it could very well be fueling the kind of indifference that seems to me to be on the rise within the mutual engagement of student and professor, I do not think it is so widespread as to threaten the idea of the first cycle of study as a space for the shared engagement of our free and creative intelligence. I can say this because when I abstract from the force of the twin expectations 
described above and consider the work I engage in with most of my colleagues and many of my students, I have no problem seeing how it engages our free and creative intelligence. However, abstracting from that force is not as simple as it sounds.

What I would like to do here is to consider how the force of the expectations that cloud our mutually free and creative intelligent engagement in study is hampered by what amounts to a kind of confusion of the distinction between what Hegel calls subjective and objective mind-our subjective psychic investments, conscious appropriations, and free, critical appreciation of the world, and our objective institutionalized patterns of interaction and the expectations that inform them. I would like to do this by considering briefly Derek Bok's critique of what, in his estimation, is happening within the first cycle of study. In a word, as the title and subtitle of his book indicate (Our Underachieving Colleges: A Candid Look at How Much Students Learn and Why They Should Be Learning More), the first cycle of study is failing both students and society because colleges are "underachieving" inasmuch as students are not learning "enough" (that is, they should be learning "more"). This is an interesting claim, but it is difficult to assess. As one reads his arguments supporting this general claim, one can see how it is a mix of the subjective impressions and expression of a long-time administrator involved in various processes of curriculum management and reform, all the while purporting to be an objective discussion of what the purposes and functions of a college are and a statement of how much college students should learn in order to qualify as graduates of such colleges.

From the subjective side, the discussion is an interesting one, as it adopts the perspective of the administrator who clearly is mindfully engaged in the first cycle of study, inasmuch as his role is to oversee and to superintend the courses of study engaged in by students and professors. And while, as we saw earlier, he is prepared to chide students about "unrealistic expectations," his real concern is with the professors (as these are grouped into faculties) and their resistance to reconsidering how their "preferred" mode of teaching (i.e., lecturing) directly contributes to the "underachievement" of students who, by certain measures, show little appreciable progress in "learning" through and completing their course of study. It would appear that getting professors to change their teaching habits is very hard work indeed.

The discussion on the objective side is more problematic and signals, I think, the beginnings of the confusion between subjective mind and objective mind mentioned above. Much of the book is structured around a discussion of the "purposes" or "objectives" of a general undergraduate education (with individual chapters devoted to the identified purposes). The purposes or objectives that are proposed -the ability to communicate (good writing, effective speaking); critical thinking; moral reasoning; preparing citizens; living with diversity; living in a more global society; fostering a breadth of interests; preparing for work-are no doubt purposes and objectives that one can find within any number of the courses that professors (through their faculties) propose through their engagement in study, with communication skills and critical thinking arguably in all of them. And, indeed, the measures Bok appeals to in claiming that students should be "learning more" have much to do with assessments of their proficiency in both communicating and thinking critically, which would seem to buttress his claim that the colleges as a whole are "underachieving." But this is to speak metaphorically, of course. The "colleges" themselves are not the subjects that develop these proficiencies; it is the students attending them 
who are afforded the opportunity to do so. Bok's complaint is that, again, according to a select number of measures and given their results, he believes this opportunity is being squandered by most students. And as an administrator, his response is to reconfigure the "course of study" in ways that more explicitly and systematically address the identified objectives; in effect, he is reframing the opportunity students are afforded in terms of those objectives by making sure, for example, that they take courses in critical thinking and moral reasoning that are taught in an appropriately measurable way, and that they are given opportunities to test their sense of what it means to live in a diverse and "global" world as the citizens they should understand themselves to be. Of course, such reframing must have the approval of the faculties, and, according to Bok, the ability to achieve these objectives is hampered by the fact that "most faculties cling to a set of practices and understandings that resist efforts to achieve effective cooperation of any sort" (p. 251).

By blaming faculties in this way, whatever recalcitrance and "clinging" to practices might exist amongst them, Bok is effectively diverting attention away from the fact that the mere identification of these objectives and their reconfiguration in the design and delivery of a general course of study (identifying outcomes) do not in themselves ensure that the opportunity they afford will be mindfully engaged (and not "squandered"). I suspect Bok would respond here by saying: Well, let's test it out. Reconfigure the program, apply the measures, and see whether the reconfigured program produces better results. This seems reasonable, but it is, in fact, deceptive. It makes it look like improving the quality of undergraduate education can be tested and thereby simply "seen" (i.e., observed) to be working, in some kind of impartial and objective way (revealed through the measures taken). However, the purported "better" results (as measured) of a reconfigured program in any given case may not be a function of the reconfiguration as such but stem rather from a renewed commitment of the faculty to its mindful engagement with undergraduate studies, merely occasioned by the reconfiguring effort. (Bok himself seems occasionally to hint that this would suit him fine, just so long as the results were actually there-which makes sense, of course, given that such results are what he, as an administrator, needs to communicate to his interlocutors, such as boards of governors, potential funders, and government officials.) The point I would like to emphasize is that, given that those results will not be achieved without the subjective mindful engagement of committed faculty, then it makes more sense to address that engagement directly rather than pretend that it needs some kind of "objective" measure to justify changing established ways of doing things. The resistance of faculty might not (only, or even primarily) be a kind of unthinking recalcitrance to change. Rather, it is probably more truthfully seen as their response to a perceived imposition on their own investment in what they are doing-that being the pursuit of knowledge out of their own free and creative intelligent engagement, which they (are expected to) profess before their students.

Now, as suggested already, I am perfectly willing to allow that some professors do not see their free and creative intelligence adequately engaged in their undergraduate courses. Insofar as they are responsible for those courses, their own lack of engagement is culpable. And insofar as disciplinary programs are geared primarily towards engaging those students who will go on to graduate study in those programs, at the expense of a broader concern for those students who do not intend to go beyond "the first cycle of study," then those programs can also be said to be betraying these other students. And 
these other students are my principal concern here, those who are committing themselves to this "first cycle of study."

What is it that we are committing to, both as students and as professors engaged in the first cycle of study? Obviously to a form of study. But how are we to distinguish it as a form of study from other forms of study (including graduate study)? To do so, perhaps we can return to the "objectives" or "purposes" of college education that Bok identifies, namely: the ability to communicate (good writing, effective speaking); critical thinking; moral reasoning; preparing citizens; living with diversity; living in a more global society; fostering a breadth of interests; preparing for work. But rather than treat the items on this list as identifying the objectives or purposes of something called college education, let us look at them in terms of how they relate to the shaping of our subjective mindful engagement, as students and professors meeting together in and around a proposed course of study. And, in the spirit of honesty, let us also recognize that our meeting together, although freely engaged, in its larger context has the appearance of being somewhat at cross purposes. The appearance of the professor in class flows less from his primary interest in the research he is pursuing than from his obligation to the program and institution that supports him in that pursuit. The appearance of the student in class flows less from her primary interest in securing a job that will be rewarding and fulfilling than from her obligation to the program and institution that will grant her a degree and thereby support her in that pursuit.

But appearances are deceiving. The professor's interest in his research is not unrelated to what he is saying in class. The student's interest in a satisfying career is not unrelated to her attentiveness in class. As a mindful engagement, what brings them together is the exercise of their free, thinking intelligence, which itself rests on their individual psychic investment and conscious appropriation of a shared world. Focusing on what appear to be their cross purposes is to restrict our concern to their individual psychic investments and conscious appropriations rather than considering the shared exercise of their free, thinking intelligence. And yet, it is when we consider the exercise of the latter that the objectives and purposes Bok identifies come more clearly into view.

Let me group them differently than the mere listing given above.

A first group describes a number of abilities: the ability to communicate clearly, both orally and in writing; the ability to think critically; the ability to reason morally.

A second group seems to point to specific particularities of the conditions within which those abilities will presumably be exercised: living with diversity; living in a more global society. The idea seems to be that, in view of these particularities, the development of the abilities of the first group should include and be understood in the context of the fostering of a breadth of interests.

A third group addresses explicitly the notion of preparation: preparing students to be citizens and preparing them for work.

What strikes me as I consider these objectives is how little there is to distinguish them as the objectives of what I have been calling "the first cycle of study." They could just as well apply to the schooling that leads up to postsecondary education. This is perhaps not surprising, given that they express broad educational objectives and purposes, which no doubt continue to remain relevant beyond the schooling we receive as children. But the question then arises: What might be their specific relation to the "first cycle of study"? 
If we take seriously the idea that this "first cycle of study" is distinct from previous forms of schooling, then we might be able to discern that distinctness in the apparent cross purposes of the students and professors who come together within it. In terms of the objectives, the students apparently engage in this cycle of study overwhelmingly as a preparation for work (understood as a meaningful career), and the professors engage in this cycle as part of the space that allows for thinking that is critical of what is merely given and for exploration of the complexities of the world (their research). What about all the other objectives identified-are they merely holdovers from the educational practices that lead up to this cycle of study? In a word, yes, even though appreciation of them will be transformed within this cycle. Why? Because what has the appearance of the cross purposes of both students and professors, in their actual encounter within the class turns out to be the creation and sustenance of the space of free, intelligent engagement itself, precisely because and insofar as it is self-consciously engaged in intelligently and freelysomething that I readily admit can be betrayed by professors who ignore their students' own efforts to think critically and by students who ignore what their professors are trying to say in connection to the students' pursuit of knowledge.

Such mutual ignorance and betrayal is certainly to be deplored, but insofar as we are here dealing with subjective mind, it is perhaps not all that surprising, especially if we take seriously the idea that our free and intelligent engagement with each other rests on our individual psychic investments in and conscious appropriations of the world. These do not go away once we engage each other creatively and freely. Indeed, these dimensions of our subjective minds may assert their rights against the work and uncertainty that goes into freely and intelligently engaging each other in the space of "not knowing" that is university study. Perhaps some professors may appear not to engage their students' own efforts because of the uncertainty they harbour about the value of what they have to say to those students, especially if the students before them are seen (and see themselves) to be primarily there out of their concern with finding a suitable career that more than likely will have little direct connection to what the professor finds most interesting and what guides her career. And perhaps some students may appear completely indifferent to what the professor is saying because they are at a loss to understand it. Such anxieties, if not acknowledged and confronted, can have perverse effects on both the teaching and the learning that are meant to be taking place in the encounter between professor and student. As David P. Levine (2011) suggests, such anxieties can feed into what he calls the fantasies harboured by both teachers and students to compensate for the uncertainty they experience as they confront each other. In these fantasies, what the teacher has to say is what the student needs to know (thus ensuring its relevance), and the knowledge the student needs to demonstrate is not something the student needs to work towards but is simply a regurgitation of what the teacher has said. Thus, a strange collusion can install itself, wherein a teacher simplifies the complexities that really interest and engage her (in her own research) so that the student can repeat them in a way that requires little effort on his part (in his quest, not to study, but to achieve the goal of obtaining a degree). As Levine puts it:

Simplification that makes the material offered by the teacher trivial validates the fantasy that the student can learn without experiencing the confusion of not knowing and the demands of thinking. Demanding that students absorb knowledge the 
teacher deems important validates the teacher's fantasy that he or she is the vital element in the learning process and that the ignorance in the teacher-student relationship resides wholly on the side of the student.

... In the classroom, the teacher's fantasy of indispensability encounters the student's fantasy of self-sufficiency. This no doubt makes the classroom a potentially explosive setting. To avoid the destructive potential in the encounter can mean finding an accommodation of the sort offered by teacher-centered learning. Within the terms of this accommodation, the student and teacher agree to restrict the objectives of teaching and learning to those that the student can achieve without undertaking a thoughtful encounter with the unknown. In particular, the student is not asked to think but only to have different thoughts, the thoughts of the teacher. Rather than a thoughtful encounter with the unknown, learning becomes the student's encounter with what is already known by the teacher. Thus the teacher is made vital to the process, and the student is not asked to learn. The student is asked to have thoughts but not to think. (Levine, 2011, pp. 160-161)

Such a situation is no doubt to be regretted, and one should not be surprised that administrators concerned, like Bok, with what students are actually learning should try to address it. However, the strategy of identifying learning "objectives" and proposing curricular reforms does not sufficiently consider the subjective (psychic, conscious, and intelligent) investments that shape the situation as a meeting of minds-the minds of the professors and the minds of the students engaged in the shared pursuit of knowledge (not its mere transmission) that brings them together. This is the challenge that needs to be addressed, not the identification of "outcomes" tailored to the measures that create their identification and formulation.

Levine's description, and the fact that we are considering our subjective mindful engagement, encourages me (a professor) to use the direct form of addressing you (a student, and indirectly other professors who share my concerns) as the free intelligence that you are and to try to express my concern as honestly as possible. I certainly agree with Levine that the classroom is a "potentially explosive setting." And as explosive, it can be destructive, even as it feeds the fantasies described above. But it can also be constructive if we are honest about the mutuality inherent in what we are engaged in doing. In fact, more than simply constructive (in the sense of building something according to a predetermined plan), the potential the classroom harbours is ultimately creative. I do not know whether what I have to say to you is something that you are prepared to take in. And you do not know what its relevance is to the rest of your life. What I have to say is interesting to me, certainly, but interesting to me precisely because it is something I deem to be interesting to you, despite the fact that I do not know this to be so. This is the professing that I do (as it connects to my own pursuit of knowledge). It is why I offer the courses that I do. What I profess may or may not help you in your quest to find a fulfilling career; in fact, it is not directed to that end, although I remain cognizant of the importance this has for you. But here, the work we are engaged in during the course of study that I propose to you is the work of thinking together, of exploring the use of your own mind in connection with what concerns me and the kind of thinking that engages me; it is a kind of thinking that is attentive to its own effort, its own engagement as a mind that so shapes itself. It 
is this notion that best characterizes the more general engagement of the first cycle of study. In the perverted form described above, being a student is demonstrating that you have acquired a certain number of thoughts (your teachers'); in the non-perverted form of our engagement, what is asked of you is not the demonstration of these thoughts but the mindful effort of your ability to think through the matters presented to you. Ultimately, this is what brings us together, this shared effort of thinking through matters in a spirit of not knowing them in advance. I (and other professors) propose to you matters to think about, and you are given the opportunity to think about them and to submit examples of the work that goes into thinking about these matters. The general objective of communicating clearly, both orally and in writing, which Bok identifies, is to be found in this work that you do in your courses. That is, the clarity of your communication stems from the effort you put into thinking for yourself about the matters proposed to you. You will find that some of the matters presented to you will prove to be more interesting to you than others (perhaps, in part, because of the particular style and enthusiasm invested in thinking about those matters that certain professors demonstrate). Because they are more interesting to you, you are able to concentrate more effectively and systematically on the work that goes into thinking about them. This increased concentration can serve as an orientation within the courses you take while you are engaged in this first cycle of study, leading you to "declare" (i.e., commit to the work required of) a concentration, or a major, or a specialization. Even for those of you who will not go on to a renewed cycle of study as a graduate (i.e., graduate studies), the point of declaring and committing to such a concentration is to allow yourself the experience of thinking further about the complexities that are revealed when matters are approached systematically and attentively. Such concentrated thinking about select matters over a number of years will give you a better sense of your own mind, your own abilities as a mindful person to appreciate the complexities that the world reveals, even if what you go on to do in your life is not directly related to the matters you worked on within this first cycle of study. When someone like Bok insists on identifying objectives for undergraduate education like "living with diversity" and "living in a global society" and fostering a "breadth of interests," what is being recognized is that the world contains complexities that we are called upon to deal with in our everyday world. Such complexity is not merely a given; it is something that can be appreciated only through the mindful activity of thinking through what presents itself to us, and it is the development of the ability to engage in such thinking through that is at the heart of the first cycle of study.

So, we are not working at cross purposes. You are studying because you want to do work that is meaningful to you. And the studies you are engaged in through this first cycle of studies do prepare you to find such meaningful work for a very important subjective reason: through them, you are afforded the opportunity to engage in a kind of mindful work that explores matters in terms of their meaningfulness, alongside others so engaged in the critical spirit of not knowing them in advance, through forms of questioning, by having any meaning and sense confront an active mind reflectively aware of its own capacity to be shaped and to shape itself. In a culture where "knowledge" and "information" are so easily accessible, but also set alongside myriad distractions, the decision to study, to engage and to explore your own mind's ability and willingness to open itself to patterns of meaning-past, present, and future-shows how meaningfulness is not a simple 
given, not something that we are merely psychically invested in and consciously aware of: meaningfulness can be freely and creatively engaged. Many students come to university precisely because they sense that what they want to do with their life is not a given, that their current psychic investment in and conscious appropriation of what the world offers does not engage what remains open to their mindful attention, and they are prepared to take more time freely and creatively to engage that attentiveness. Such considered attentiveness is precisely what professors have to offer them, insofar as their own psychic investments in and conscious appropriation of the world have led them freely and creatively to engage their own minds and to contribute to certain modes of investigation and questioning-including the explorations of results and hypotheses-in a such a way that they are willing to share a space (the classroom) with similarly engaged students. And the value of such a shared engagement is, quite literally, immeasurable.

\section{Contact Information}

Réal Fillion

Department of Philosophy

University of Sudbury

rfillion@usudbury.ca

Réal Fillion is associate professor of philosophy at the University of Sudbury, a federated university of Laurentian University. He is the author of Multicultural Dynamics and the Ends of History: Exploring Kant, Hegel, and Marx and Foucault and the Indefinite Work of Freedom, both from University of Ottawa Press.

\section{References}

Bok, Derek. (2006). Our underachieving colleges: A candid look at how much students learn and why they should be learning more. Princeton, NJ: Princeton University Press.

Hegel, G.W.F. (2007). Philosophy of mind (W. Wallace \& A.V. Miller, Trans.). Oxford, UK: Clarendon Press. (Original work published 1830)

Levine, David P. (2011). The capacity for civic engagement: Public and private worlds of the self. New York, NY: Palgrave Macmillan.

MacIntyre, Alasdair. (2009). God, philosophy, universities: A history of the catholic philosophical tradition. London, UK: Continuum.

Whitehead, Alfred North. (1967). The aims of education and other essays. New York, NY: The Free Press. (Original work published 1929)

Winfield, Richard Dien. (2010). Hegel and mind: Rethinking philosophical psychology. Houndmills, UK: Palgrave Macmillan. 